\title{
CARACTERIZAÇÃO DA SILAGEM DE GRÃO DE MILHO REIDRATADO ASSOCIADO AO RESÍDUO DE TILÁPIA
}

\section{CHARACTERIZATION OF SILAGE OF REHYDRATED CORN GRAIN ASSOCIATED WITH TILAPIA RESIDUE}

\author{
Núbia Regiane Bueno de Ávila1 ORCID http://orcid.org/0000-0003-4994-8532 \\ Nhayandra Christina Dias e Silva ${ }^{1}$ ORCID http://orcid.org/0000-0003-1804-8312 \\ Rafael Fernandes Leite ${ }^{1}$ ORCID http://orcid.org/0000-0002-4499-9288 \\ Larissa de Ávila Barbosa ${ }^{1}$ ORCID http://orcid.org/0000-0001-8630-5603 \\ Ligiane Aparecida Florentino ${ }^{1}$ ORCID http://orcid.org/0000-0001-9092-3017 \\ Adauton Vilela de Rezende ${ }^{{ }^{*}}$ ORCID http://orcid.org/0000-0001-8515-484X
}

1 Universidade José do Rosário Vellano - UNIFENAS, Alfenas, MG, Brasil.

*Autor para correspondência - adauton.rezende@unifenas.br

\section{Resumo}

Objetivou-se avaliar as características bromatológicas, microbiológicas e perdas fermentativas da silagem de grão de milho reidratado com água ou soro de leite associado a diferentes níveis de inclusão do resíduo de tilápia. Utilizou-se um delineamento inteiramente casualizado em esquema fatorial 5x2 (cinco níveis de inclusão do resíduo de tilápia: 0; 12,5; 25; 37,5 e 50\% em substituição ao milho reidratado e duas fontes de reidratação do grão de milho: água ou soro de leite) para produção de silagem). A produção de gases da silagem com até 25\% de inclusão do resíduo de tilápia foi $62,7 \%$ maior para o milho reidrato com soro de leite $(\mathrm{P}<0,01)$. A quantidade de bactérias ácido láticas foi menor em todos os níveis de inclusão de resíduo de tilápia quando a fonte de reidratação foi a água $(\mathrm{P}<0,01)$. Os teores de matéria mineral, matéria orgânica, proteína bruta, extrato etéreo, cálcio e fósforo foram maiores nas silagens reidratadas com soro de leite com o aumento do nível de inclusão de resíduo de tilápia $(\mathrm{P}<0,01)$. A silagem de resíduo de tilápia com milho reidratado é uma alternativa que pode ser utilizada na dieta de aves e suínos, entretanto, o seu uso está condicionado às avaliações do melhor nível de inclusão dentro de uma categoria animal.

Palavras-chave: Alimento alternativo. Fermentação. Resíduo de pescado. Soro de leite.

\begin{abstract}
The objective of this study was to evaluate the microbiological, chemical characteristcs and fermentative losses of corn silage rehydrated with water or whey associated to different levels of tilapia residue inclusion. A completely randomized design was used in a $5 \times 2$ factorial arrangement (five inclusion levels of tilapia residue: $0 ; 12.5 ; 25 ; 37.5$ and $50 \%$ in substitution of dehydrated corn; and two sources of rehydration of corn: water or whey) for silage production. The production of gases of the silage with up to $25 \%$ inclusion of the tilapia residue was $62.7 \%$ greater for the corn rehydrate with whey $(\mathrm{P}<0.01)$. The amount of lactic acid bacteria was lesser for all levels of inclusion of tilapia residue when the source of rehydration was water $(\mathrm{P}<0.01)$. The levels of mineral matter, organic matter, crude protein, ethereal extract, calcium and phosphorus were greater in silages rehydrated with whey with the increase of the inclusion level of tilapia residue $(\mathrm{P}<0.01)$. Tilapia residue silage with rehydrated corn is an alternative that can be used in the poultry and swine diet, however, its use
\end{abstract}


is conditioned to the evaluation of the best level of inclusion within an animal category.

Keywords: Alternative food. Fermentation. Tilapia residue. Whey.

Recebido em: 13 de novembro de 2017.

Aceito em: 07 de maio de 2019.

\section{Introdução}

O milho é um dos principais ingredientes que compõe a dieta dos animais por ser um alimento rico em carboidratos solúveis e possuir alta digestibilidade ${ }^{(1)}$. Contudo, o alto custo desse ingrediente tem aumentado a constante busca por alimentos alternativos que suprem às exigências nutricionais dos animais e que sejam economicamente viáveis para substituí-los nas dietas, visando maior eficiência produtiva e econômica na produção animal.

A técnica de reidratação do grão de milho tem possibilitado melhoras no padrão de fermentação e nos aspectos nutritivos ${ }^{(2)}$, além de trazer como vantagem sua produção em qualquer época do ano, visto que o grão de milho pode ser adquirido de terceiros e reidratado na própria fazenda. Uma possível alternativa para a reidratação do grão de milho seria utilizar o soro de leite como veículo de reidratação, uma vez que ele é um dos subprodutos mais poluentes da indústria de alimentos ${ }^{(3)}$ e sua natureza perecível não permite a estocagem por períodos prolongados, surgindo então a necessidade de se utilizar alguma técnica de conservação para dar um novo destino e melhorar o aproveitamento desse subproduto, pois apesar do seu reconhecido valor nutritivo, o soro continua sendo considerado um resíduo ${ }^{(4)}$.

A tilápia do Nilo (Oreochromis niloticus) é um dos peixes mais comercializados no país, sendo que a sua comercialização se dá principalmente por meio da filetagem, em que cerca de $70 \%$ do animal é descartado, resultando em grandes volumes de resíduo ${ }^{(5)}$. Apesar desse resíduo possuir alto valor proteico, trata-se de um alimento altamente perecível e por isso é considerado um dejeto, causando prejuízos ecológicos, sanitários e econômicos ${ }^{(6)}$.

De acordo com Berenz ${ }^{(7)}$, o resíduo de tilápia tem grande potencial de utilização na alimentação de não ruminantes, contanto que seja utilizado um método de conservação do material. Dessa forma, o processo de ensilagem, o qual permite a conservação do alimento em meio anaeróbico ${ }^{(8)}$, surge como um método viável de conservação tanto do resíduo de tilápia quanto do soro do leite para a sua utilização na alimentação animal, uma vez que o princípio básico da silagem biológica é a fermentação de carboidratos por microrganismos, com produção de ácidos orgânicos e, consequentemente, redução do pH da massa ensilada para a sua conservação.

Diante desse contexto, o objetivo deste estudo foi avaliar as características bromatológicas e microbiológicas, bem como as perdas fermentativas da silagem de grão de milho reidratado com água ou soro de leite associado a diferentes níveis de inclusão do resíduo de tilápia em substituição ao milho reidratado.

\section{Material e métodos}

O experimento foi conduzido na Faculdade de Agronomia da Universidade José do Rosário Vellano, 
Campus de Alfenas - MG, e o delineamento experimental utilizado foi inteiramente casualizado (DIC) em esquema fatorial de 5x2 (cinco níveis de inclusão do resíduo de tilápia: 0; 12,5; 25; $37,5 \mathrm{e}$ $50 \%$ em substituição ao grão de milho reidratado, com água ou com soro de leite, para a produção de silagem), totalizando 10 tratamentos com quatro repetições em cada tratamento.

Para a produção da silagem de milho, foi adquirido o grão de milho com textura dura e toda a umidade do grão foi retirada (em torno de 14\%). Posteriormente, o grão de milho foi moído para obtenção de partículas de $4 \mathrm{~mm}$, sendo que o procedimento foi realizado antes da reidratação e do processo de ensilagem.

O resíduo de tilápia do Nilo (Oreochromis niloticus) utilizado na elaboração da silagem foi moído para possibilitar melhor homogeneização do material. A composição química do milho seco moído e do resíduo de tilápia (in natura) estão apresentados Tabela 1.

O soro de leite utilizado para reidratação do grão de milho foi resultante da coagulação enzimática do leite, derivado da fabricação de queijo artesanal na região sul de Minas Gerais. Esse soro foi homogeneizado e analisado quanto à densidade, acidez, crioscopia, $\mathrm{pH}$, matéria seca (MS), proteína bruta (PB) e extrato etéreo (EE), de acordo com os procedimentos indicados nas Normas Analíticas do Instituto Adolfo Lutz ${ }^{(9)}$ (Tabela 2).

Tabela 1. Composição química do milho seco moído e resíduo de tilápia (in natura)

\begin{tabular}{llc}
\hline Composição & Milho & Resíduo de Tilápia \\
\hline Matéria Seca (MS), \% & 86,02 & 31,08 \\
Matéria orgânica (MO), \% MS & 98,84 & 94,98 \\
Matéria mineral (MM), \% MS & 1,16 & 16,2 \\
Proteína bruta (PB), \% MS & 8,25 & 26,6 \\
Extrato etéreo (EE), \% MS & 3,42 & 49,7 \\
Cálcio (Ca), \% MS & 0,04 & 10,2 \\
Fósforo (P), \% MS & 0,25 & 3,5 \\
\hline
\end{tabular}

Fonte: Os autores.

Tabela 2. Composição química do soro de leite integral

\begin{tabular}{lc}
\hline Componente & Soro de leite integral \\
\hline Densidade, g/L a $15^{\circ}$ & 1.02 \\
Acidez, ${ }^{\circ} \mathrm{D}$ & 16,50 \\
Crioscopia, ${ }^{\circ} \mathrm{H}$ & $-0,74$ \\
$\mathrm{pH}$ & 5,30 \\
Matéria seca (MS), \% & 13,8 \\
Lactose, \% MS & 62,7 \\
Proteina bruta (PB), \% MS & 9,7 \\
Extrato etéreo (EE), \% MS & 18,9 \\
\hline
\end{tabular}

Fonte: Os autores. 
Para a reidratação do grão de milho com água ou soro de leite, foi considerado o teor de $35 \%$ de umidade. A quantidade de líquido para a reconstituição da umidade foi calculada de acordo com a equação adaptada por Ferreira $^{(10)}$ :

$$
\Delta \mathrm{H}_{2} \mathrm{O}=\left\{\frac{\left[\frac{\mathrm{UM} \times(\mathrm{Uf}-\mathrm{Ui})}{100-\mathrm{Uf}}\right]}{\mathrm{p}}\right\}
$$

em que:

$$
\begin{aligned}
& \Delta \mathrm{H}_{2} \mathrm{O}=\text { volume de água a ser adicionada; } \\
& \mathrm{UM}=\text { massa do produto úmido em } \mathrm{kg} ; \\
& \mathrm{Uf}=\text { umidade final em } \% ; \\
& \mathrm{Ui}=\text { umidade inicial em } \% ; \\
& \mathrm{v}=\text { massa específica da água ou soro de leite em } \mathrm{kg} / \mathrm{L} .
\end{aligned}
$$

Após a moagem do resíduo de tilápia e realizada sua homogeneização, bem como a reidratação do milho com água ou soro de leite, ambos os materiais foram pesados e homogeneizados. Posteriormente, foi realizada a homogeneização dos materiais de acordo com os níveis de inclusão do resíduo de tilápia $(0 ; 12,5 ; 25 ; 37,5$ e $50 \%$ com base na matéria natural) em substituição ao grão de milho reidratado para a produção da silagem, o que equivale em $0 ; 3,88 ; 7,76 ; 11,64$ e $15,5 \%$ de matéria seca adicionada, respectivamente. A massa resultante foi ensilada em silos experimentais de tubos de PVC com 0,40 $\mathrm{m}$ de altura e $0,10 \mathrm{~m}$ de diâmetro, com capacidade para 4 litros.

A compactação foi realizada com auxílio de soquetes de madeira com acomodação de camadas de aproximadamente $5 \mathrm{~cm}$ de espessura, até obter uma densidade de aproximadamente $650 \mathrm{Kg} / \mathrm{m}^{3}$. Após a compactação, os silos foram novamente pesados e fechados com tampa adaptada com válvula tipo Bunsen para o escape de gases, lacrados com fita, pesados novamente e levados para uma sala onde permaneceram por um período de 90 dias.

Decorrido esse período, ou seja, 90 dias, os silos foram pesados e abertos. Para determinação da perda por gases (PG), foi realizada a subtração do peso dos silos cheios na ensilagem e antes da abertura, utilizando a equação de Jobim et al. ${ }^{(11)}$ :

$$
P G=\frac{\{[(\text { PCen }- \text { Pen }) \times \text { MSen }]-[(\text { Pcab }- \text { Pen }) \times \text { MSab }]\}}{[(\text { PCen }- \text { Pen }) \times \text { MSen }]} \times 100
$$

em que:

$P G=$ perdas por gases $(\%$ da $M S)$;

$\mathrm{PCen}=$ peso do silo cheio na ensilagem $(\mathrm{kg})$;

Pen $=$ peso do conjunto (tubo, tampa, areia e tela) na ensilagem $(\mathrm{kg})$;

MSen = teor de MS na ensilagem (\%);

$\mathrm{PCab}=$ peso do silo cheio na abertura $(\mathrm{kg})$;

$\mathrm{MSab}=$ teor de MS na abertura (\%). 
Após a abertura do silo, foi retirado o terço mediano do material de cada silo e após sua homogeneização, uma amostra foi retirada para determinação do pH (potenciômetro Beckmam Expandomatic SS-2), composição bromatológica e microbiológica.

Para a determinação da composição bromatológica da silagem, as amostras coletadas foram pré-secas em estufa com circulação forçada de ar a $55^{\circ} \mathrm{C}$ por 72 horas, moídas em moinho do tipo Willey com peneira de crivos de $1 \mathrm{~mm}$ e guardadas em recipientes plásticos para posteriores análises. Foram determinados, segundo a $A O A C^{(12)}$, o teor de matéria seca (MS), proteína bruta $(\mathrm{PB})$, extrato etéreo $(\mathrm{EE})$, matéria mineral $(\mathrm{MM})$, cálcio $(\mathrm{Ca})$ e fósforo $(\mathrm{P})$. A concentração de $\mathrm{Ca}$ e $\mathrm{P}$ foi determinada por espectrofotometria de chama.

Foi realizada a contagem de microrganismos nas amostras e quantificados os seguintes microrganismos em seus respectivos meios de cultura semi-seletivos: coliformes totais (Ágar PCA), coliformes fecais (Eschererichia coli - Ágar Violeta Red Bile), Salmonela spp., bactéria ácido láticas (Ágar Rogosa), bolores e leveduras (Ágar BDA). As análises microbiológicas seguiram os protocolos propostos por Silva et al. ${ }^{(13)}$, e o plaqueamento foi realizado em triplicata para cada diluição e meio de cultura. As placas com Ágar BDA foram colocadas em B.O.D $\left(36^{\circ} \mathrm{C}\right)$, enquanto as demais foram colocadas em estufa a $35,5^{\circ} \mathrm{C}$. A contagem das placas iniciou 48 horas após o plaqueamento e foram consideradas passíveis de contagem apenas placas que apresentaram entre 3 e 30 unidades formadoras de colônia.

Para a detecção, isolamento e identificação de Salmonella spp., foi utilizada a metodologia segundo os padrões e metodologias da Americam Public Health Association, descrita no Compendium of Methods for the Microbiological Examination of Foods ${ }^{(14)}$. Após o período de incubação, foram feitas estrias compostas nos meios semi-seletivos ágar HE e ágar Salmonella - Shigella (SS), cujas placas foram incubadas a $35^{\circ} \mathrm{C}$ por um período de $24 \mathrm{~h}$.

Por sua vez, para o isolamento dos fungos, foi utilizado o meio Dicloran Rosa Bengala Cloranfenicol (DRBC), por sete dias a $25^{\circ} \mathrm{C}$. Posteriormente, os fungos isolados foram purificados em meio Malte Agar (MA) e cultivados a $25^{\circ} \mathrm{C}$, durante sete dias. Em seguida, as culturas puras foram transferidas para os meios Ágar Extract Malt (MEA) e Czapeck Yeast Ágar (CYA) e incubadas às temperaturas de $25^{\circ} \mathrm{C}$ e a $37^{\circ} \mathrm{C}$, por sete dias ${ }^{(15)}$. Os isolados foram identificados morfologicamente e quanto à sua estrutura em microscópio óptico.

Os dados foram submetidos à análise de variância pelo programa estatístico $\mathrm{SAS}^{(16)}$, sendo que os níveis de inclusão de resíduo de tilápia foram avaliados por contrastes ortogonais lineares e quadráticos. A fonte utilizada para reidratação do grão de milho (água ou soro de leite) foi comparada pelo teste $\mathrm{F}$ para avaliar os efeitos das perdas durante a ensilagem e determinar a composição bromatológica e microbiológica da silagem.

\section{Resultados e Discussão}

Houve efeito de interação entre os níveis de inclusão do resíduo de tilápia e a fonte de reidratação do grão de milho da silagem para a produção de gases, perda de MS e $\mathrm{pH}(\mathrm{P}<0,01$; Tabela 3$)$.

A produção de gases da silagem com até $25 \%$ de inclusão do resíduo de tilápia foi $62,7 \%$ maior para o grão de milho reidrato com soro de leite em relação à água $(\mathrm{P}<0,01)$. Quando o nível de inclusão aumentou para 37,5\% e 50\% na silagem, a produção de gases foi similar em ambas fontes de reidratação $(\mathrm{P}<0,01)$. 


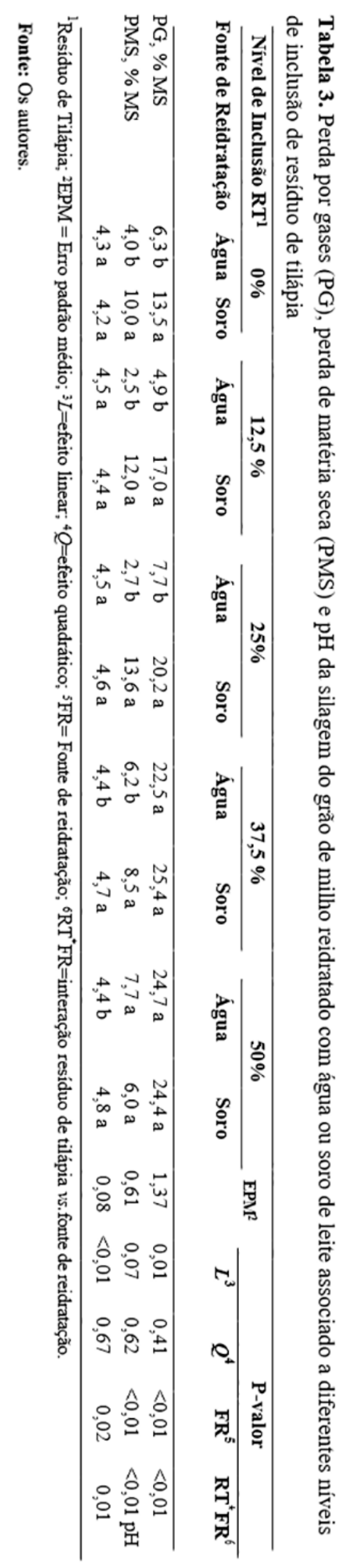

Cienc. anim. bras., Goiânia, v.20, 1-12, e-50220, 2019 
A perda de MS da silagem com inclusão dos níveis de $0 \%, 12,5 \%, 25 \%$ e 37,5\% do resíduo de tilápia foi maior com a utilização do soro de leite do que com a água como fonte de reidratação. Quando o nível de inclusão do resíduo de tilápia foi de $50 \%$, não houve diferença entre as fontes de reidratação $(\mathrm{P}<0,01)$.

Com a inclusão de até $25 \%$ do resíduo de tilápia, o $\mathrm{pH}$ da silagem foi similar para a reidratação do grão de milho tanto com água quanto com soro do leite. Entretanto, quando o nível de inclusão aumentou para $37,5 \%$ e $50 \%$, o $\mathrm{pH}$ da silagem reidratada com soro do leite foi maior em relação à silagem reidratada com a água $(4,8$ vs. 4,$4 ; \mathrm{P}<0,01)$.

O aumento da produção de gases (PG) e a perda de MS até os níveis intermediários de inclusão de resíduo de tilápia na silagem relacionado à reidratação do grão de milho com soro de leite em relação à água, possivelmente, está associado à maior fermentação dos carboidratos solúveis presentes no material ensilado, principalmente, devido à fermentação da lactose, a qual é o principal açúcar presente no soro do leite, o que, consequentemente, resultou na diminuição da MS pelo processo fermentativo para maior produção de ácidos orgânicos na silagem.

A partir do momento em que o nível de inclusão de resíduo de tilápia em substituição ao milho se tornou maior, o efeito da reidratação do grão com soro de leite na produção de gases fora similar ao da água, o que pode ser explicado pela ausência de carboidratos para fermentação e produção de ácidos orgânicos, uma vez que o resíduo de tilápia apresenta grande quantidade de água em sua composição (Tabela 1). Adicionalmente, a PG e a perda de MS proveniente da inclusão do resíduo de tilápia em substituição ao milho podem ter promovido alterações no processo fermentativo, impedindo o rápido decréscimo do $\mathrm{pH}$ e favorecendo fermentações secundárias ${ }^{(17)}$.

De acordo com Vilela ${ }^{(18)}$, o limite superior de $\mathrm{pH}$ para as silagens de boa qualidade seria em torno de 4,2, logo, quando o $\mathrm{pH}$ é muito acima desse valor, é possível inferir que o processo de fermentação da silagem foi inadequado. Neste estudo, a maior quantidade de água presente na silagem com a inclusão de resíduo de tilápia pode ter prejudicado o processo fermentativo e a produção de ácidos, propiciando maior $\mathrm{pH}$.

Outro aspecto que deve ser ponderado, é que os níveis altos de inclusão de resíduo de tilápia associado ao soro do leite, os quais possuem um alto teor proteico, baixo teor de carboidratos solúveis e alta concentração de minerais, são menos aptos a sofrerem fermentação mais intensa e com isso pode ocorrer maior proteólise durante o processo de ensilagem. Entretanto, o teor de proteína não seria a única causa de tamponamento, uma vez que minerais como o cálcio podem também contribuir com íons nos sistemas tampões. Leonel et al. ${ }^{(19)}$, ao avaliarem as características qualitativas de vários tipos de silagens, concluíram que os elevados teores de proteína e MM dificultam a conservação da silagem, em decorrência do aumento da concentração de amônia e elevada capacidade tamponante. Além desses fatores, as características microbiológicas do soro de leite podem influenciar diretamente nas produções de gases e perdas na MS da silagem. Adicionalmente, a presença das bactérias do grupo coliformes pode fermentar a lactose, aumentando a produção de gases ${ }^{(20,21)}$, resultando na produção e liberação de gás carbônico pelos microrganismos ${ }^{(22)}$.

O baixo $\mathrm{pH}$ da silagem é fundamental para inibir o crescimento de bactérias dos gêneros Staphylococcus, Escherichia, Serratia, Enterobacter, Citrosactu, Achromobacter e Pseudomonas ${ }^{(23)}$, até porque elas podem causar infecções e/ou intoxicações gastrointestinais graves ${ }^{(24)}$. Entretanto, o maior $\mathrm{pH}$ observado neste estudo em níveis maiores de inclusão de resíduo de tilápia pode ter contribuído para o desenvolvimento de fungos e leveduras, o que pode estar associado à maior degradação de matéria seca e perda de qualidade da silagem. Nesse contexto, Muck et al. ${ }^{(25)}$ ressaltaram que a 
deterioração da silagem está associada principalmente ao aparecimento de fungos e leveduras que apresentam alta resistência as variações de $\mathrm{pH}$. Essas leveduras provocam grande liberação de $\mathrm{CO}_{2}$ pelo metabolismo dos açúcares, resultando em perdas de MS, além da liberação de calor provocar aumento na concentração dos produtos da reação de Maillard.

Houve efeito de interação entre os níveis de inclusão de resíduo de tilápia e fonte de reidratação para contagem de bactérias ácido láticas ( $\mathrm{P}<0,01$; Tabela 4). A densidade populacional (UFC/g de silagem) dessas bactérias (BALs) foi maior em todos os níveis de inclusão de resíduo de tilápia quando o grão de milho da silagem foi reidratado com soro de leite em relação à água $(\mathrm{P}<0,01)$.

A associação do soro de leite, milho e resíduo de tilápia favoreceu o crescimento de BALs, o que já era esperado, uma vez que a presença de lactose no soro de leite estimula o seu crescimento ${ }^{(3)}$. Dessa forma, as BALs apresentaram papel fundamental no processo de ensilagem, pois além de inibir o crescimento de microrganismos deterioradores, possibilitaram maior recuperação da energia dos carboidratos fermentados por meio da produção de ácido lático ${ }^{(26)}$.

Houve presença de coliformes nos níveis de inclusão de resíduo de tilápia na silagem em que o soro de leite foi utilizado como fonte de reidratação (Tabela 4). Chiappini et al. ${ }^{(26)}$ destacaram que, como o soro do leite é um produto de vida útil curta, devido às condições de umidade e $\mathrm{pH}$, e que, por sua vez, são favoráveis ao crescimento microbiano, a contaminação por coliformes é um fator que deve ser considerado. Soares et al. ${ }^{(27)}$, ao analisarem a população microbiológica do soro de leite cru ou pasteurizado para produção de iogurtes, verificaram alta carga microbiológica para as variáveis analisadas (coliformes, E. coli, bolores e leveduras) para o soro de leite cru. Portanto, podese inferir que a maior prevalência do grupo coliformes nesta pesquisa, provavelmente, ocorreu devido à presença desses microrganismos no soro de leite utilizado como fonte de reidratação do milho, o que pode ter acarretado em perda de qualidade da silagem.

Não foram observadas a presença de Salmonella e de Escherichia coli no presente estudo. A legislação vigente (portaria $n^{\circ}$ 451, de setembro de 1997 do Ministério da Saúde) não estabelece padrões microbiológicos para silagem de tilápia, por esse motivo, utilizam como base os parâmetros existentes para peixe fresco. Os resultados encontrados neste trabalho condizem com o padrão exigido pela legislação vigente. No entanto, foi detectado o crescimento de fungos e leveduras que, após a identificação morfológica e microscópica, foram classificados como pertencentes aos gêneros Aspergillus spp; Peniciliumm e Fusarium.

A porcentagem de MS diminuiu quadraticamente com a inclusão de resíduo de tilápia, sendo o menor valor observado na inclusão de $50 \%(\mathrm{P}<0,01$; Tabela 5). Esse resultado já era esperado, visto que há uma diminuição dos teores de MS em função do acréscimo de resíduo de tilápia nas silagens, uma vez que o resíduo de tilápia é composto principalmente por água, conforme discutido anteriormente.

Houve efeito de interação entre os níveis de resíduo de tilápia na silagem e fonte de reidratação para MM, MO, PB, EE, Ca e P ( $<<0,01$; Tabela 5). De modo geral, os teores de MM, MO, PB, EE, Ca e P apresentaram-se maiores na silagem em que o grão de milho foi reidratado com soro de leite à medida que aumentou o nível de inclusão de resíduo de tilápia na silagem $(\mathrm{P}<0,01$; Tabela 5).

O decréscimo no teor de matéria mineral relaciona-se com a alta concentração de minerais presentes na silagem com o aumento da inclusão de resíduos de tilápia, somado ao teor de minerais encontrados no soro de leite. Haard et al. ${ }^{(28)}$ constataram que a silagem de pescado apresenta altos teores de minerais, devido a utilização de diferentes partes do peixe (cabeça, escamas, pele e espinha). Dessa forma, a adição do soro de leite contribuiu ainda mais para o acréscimo na concentração de minerais, sobretudo de $\mathrm{Ca}$ e $\mathrm{P}$, uma vez que o soro é considerado fonte destes macrominerais ${ }^{(29)}$. 

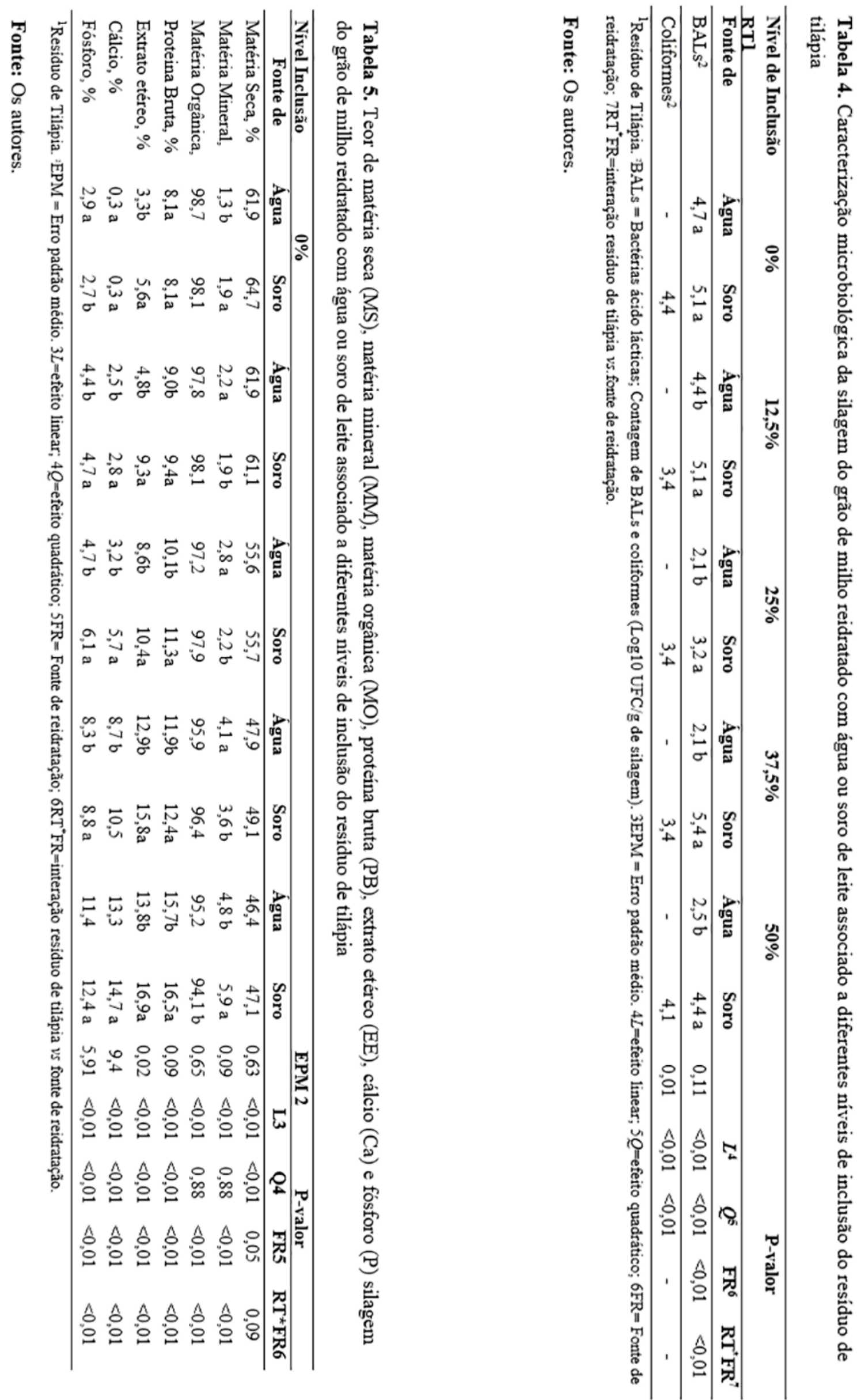
A maior concentração de PB e EE na silagem reidratada com soro de leite com o aumento do nível de inclusão do resíduo de tilápia provavelmente está atribuída ao maior teor de PB e EE presente na composição do soro (Tabela 2), associado ao teor de PB e EE do resíduo de tilápia (Tabela 1). Segundo Ramos et al. ${ }^{(30)}$, os lipídios provenientes da silagem de resíduo de tilápia podem reduzir a excessiva solubilização da proteína no material, contudo, a presença de óleo juntamente aos altos níveis de ácidos graxos poli-insaturados, que estão sujeitos à oxidação, pode tornar a silagem não palatável e imprópria ao consumo do animal. Além disso, altas concentrações de PB prejudicam a conservação da silagem devido à alta concentração de amônia no material e alteração da capacidade de tamponamento ${ }^{(19)}$.

De um modo geral, a silagem de resíduo de tilápia com milho reidratado é uma alternativa que pode ser utilizada na dieta de aves e suínos, visto que é um alimento energético, com alto nível proteico e possui perfil de aminoácidos essenciais. $\mathrm{O}$ alto teor de extrato etéreo presente no material permite uma dieta de maior densidade energética, o que pode resultar num melhor custo/benefício na produção animal.

\section{Conclusão}

A silagem de grão de milho reidratado (com água ou soro de leite) associado ao resíduo de tilápia, devido às suas características, mostrou ser um produto com alto valor proteico e energético, bem como fonte de Ca e P com até $25 \%$ de inclusão do resíduo. Entretanto, o seu uso está condicionado às avaliações do melhor nível de inclusão na dieta para promover melhor desempenho dentro de uma categoria animal e fase fisiológica específica. É importante se atentar ao uso de soro de leite quanto à composição microbiológica, visto que seu uso possibilita alteração na qualidade da silagem.

\section{Referências}

1. Schalch FJ, Schalch E, Zanetti MA, Brisola ML. Substituição do milho em grão moído pela polpa cítrica na desmama precoce de bezerros leiteiros. Revista Brasileira de Zootecnia. 2001; 30(1), 280-285.

2. Shabi Z, Bruckental I, Zamwell S, Tagari H, Arieli A. Effects of extrusion of grain and feeding frequency on rumen fermentation, nutrient digestibility, and milk yield and composition in dairy cows. Journal of Dairy Science. 1999; 82(6), 1252-1260.

3. Oliveira DF, Bravo CE, Tonial IB. Soro de leite: um subproduto valioso. Revista do Instituto de Laticínios Cândido Tostes. 2012; 67(385), 64-71.

4. Souza JRM, Bezerra JRMV, Bezerra AKN. Utilização do soro de queijo na elaboração de pães. Revista Ciências Exatas e Naturais. 2005; 7(1), 91-102.

5. Souza MLR. Comparação de Seis Métodos de Filetagem, em Relação ao Rendimento de Filé e de Subprodutos do Processamento da Tilápia-do-Nilo (Oreochromis niloticus). Revista Brasileira de Zootecnia. 2002; 31(3), 1076-1084.

6. Machado TM. Silagem biológica de pescado. Panorama da Aqüicultura. 1998; 8(47), 30-32.

7. Berenz Z. Ensilado de residuos de pescado. In: Procesamiento De Ensilado De Pescado. Itp/Jica, XIV Curso Internacional Tecnología de Procesamiento de Productos Pesqueros, 1998. p. 17 - 71. Spanish. 
8. Rezende AV, Rabelo CHS, Veiga RM, Andrade LP. Rehydration of corn grain wich acid whey improves the silage quality. Animal Feed Science and Technology. 2014; 197(1), 213-221.

9. Instituto Adolfo Lutz. Normas Analíticas do Instituto. Adolfo Lutz: Métodos Químicos e Físicos para Análise de Alimentos. 3 ed. São Paulo: Imprensa Oficial do Estado de São Paulo, 1985. Portuguese.

10. Ferreira WA. Armazenamento de grãos de cereais. In: Manual de armazenamento e embalagem de produtos agropecuários. Cereda. M. P.; Sanches, L. (Eds). FEPAF. UNESP. Botucatu. 1983, p. 96-128. Portuguese.

11. Jobim CC. Avaliação das características microbiológicas, químicas e digestibilidade das silagens de grãos úmidos e de espiga de milho. 1996. 98p Tese (Doutorado em Zootecnia) - Faculdade de Ciências Agrárias e Veterinária, Universidade Estadual Paulista, Jaboticabal, 1996.

12. Association of Official Analitycal Chemists. AOAC. Official Methods Of Analysis.15 Ed. Washington, 1995. English.

13. Silva N, Junqueira VCA, Silveira ANF. Manual de Métodos de Análises Microbiológicas de Alimentos. São Paulo, 1997. 295p. Portuguese.

14. APHA. American Public Health Association. Compendium of the Methods for the Microbiological Examination of Foods. 4th. Washington, 2001. 676 p. English.

15. Rezende EF, Couto FA, Borges JG, Silva DM, Batista LR. Potencial Enzimático e Toxigênico de Fungos Isolados de Grãos de Café. Coffee Science. 2013; 8(1), 69-77.

16. SAS Institute. Statistical Analysis System: user guide [CD-ROM]. Version 8. Cary (NC): SAS Institute Inc., 2002.

17. Ítavo LCV, Santos GT, Jobim CC. Consumo e Digestibilidade Aparente da Silagem de Bagaço de Laranja. In: Reunião da Sociedade Brasileira de Zootecnia. Anais... Botucatu, SP. 1998; 388-390.

18. Vilela D. Aditivos para Silagem de Plantas de Clima Tropical. In: Simpósio Sobre Aditivos na Produção de Ruminantes e Não Ruminantes. In: Reunião da Sociedade Brasileira de Zootecnia. Anais... Botucatu, SP. 1998, p. 73-108.

19. Leonel FP, Pereira JC, Costa MG, Marcojúnior P, Lara LA, Sousa DP, Silva CJ. Consórcio Capim-Braquiária e Soja, Produtividade das Culturas e Características Qualitativas das Silagens. Revista Brasileira de Zootecnia. 2008; 37(11), 2031-2040.

20. Grandi AZE, Rossi DA. Qualidade Microbiológica do Queijo Minas Frescal Comercializado na Cidade de Uberlândia-MG. In: VI Encontro Interno de Iniciação Científica. Anais... Uberlândia, MG. 2006, p. 120.

21. Silva MP, Cavalli DR, Oliveira TCRM. Avaliação do Padrão Coliformes a $45^{\circ} \mathrm{C}$ e Comparação da Eficiência das Técnicas dos Tubos Múltiplos e Petrifilm EC na Detecção de Coliformes Totais e E. Coli em Alimentos. Ciência e Tecnologia Alimentos. 2006; 26(1), 352-359.

22. Furtado MM. Fermentação Propiônica em Queijos: Conhecimentos Recentes sobre a Produção de Olhadura. Revista do Instituto de Laticínios Cândido Tostes. 2007; 62(357), 01-14.

23. Vidotti RM, Gonçalves GS. Produção e Caracterização de Silagem, Farinha e Óleo de Tilápia e sua Utilização na Alimentação Animal. Centro Avançado de Pesquisa Tecnológica do Agronegócio do Pescado Continental Instituto de Pesca-APTA-SAA. São José do Rio Preto, SP, Brasil. 2006.

24. Valsechi AO. Microbiologia Dos Alimentos. São Paulo: Universidade Federal de São Carlos, 2006. 48p. Portuguese. 
25. Muck RE, Shinnes KJ. Conserved Forages (Silage and Hay): Progress and Proprities. In: Internacional Grassland Congress. Proceedings...Piracicaba: Brazilian Society of Animal Husbandry. 2001; p. 753-762.

26. Chiappini CJJ, Franco RM, Oliveira LAT. Avaliação do Soro de Queijo quanto aos Coliformes totais e Coliformes Fecais. Revista do Instituto de Laticínios Cândido Tostes. 1995; 50(1), 253- 257.

27. Soares DS, Fai AEC, Oliveira AM, Pires EMF, Stamford TLM. (2011). Aproveitamento de soro de queijo para produção de iogurte probiótico. Arquivo Brasileiro de Medicina Veterinária e Zootecnia, 2011; 63(4), 996-1002.

28. Haard NF, Kariel N, Herzberg G, Feltham LA, Winter K. Stabilisation of protein and oil in fish silage for use as a ruminant feed supplement. Journal of the Science of Food and Agriculture. 1985; 36(4), 229-241.

29. Vargas CNO. Aproveitamento do Soro de Queijo Coalho para Obtenção de Iogurte Tipo Líquido de Soja e Avaliação Química, Físico Química, Microbiológica e Sensorial do Produto. (Dissertação de mestrado) 2002. 103p. Universidade Federal Da Paraíba.

30. Ramos OV, Dorado MDP, Caro EO. Ensayo sobre la alimentacion de la cachama negra (colossoma macropomum) com pescado en acidos organico e inorganico (Fish silage). Boletin Cientifico - INPA. 1994; 2(1) 46-61. 